\title{
¿Perpetúan las normas la discriminación hacia las mujeres? De la necesidad del análisis de la producción legal en Colombia
}

\author{
Do norms perpetuate discrimination against women? \\ Regarding the need of an analysis of legislative production in Colombia
}

Ginna Lizeth González Cortés*

Fecha de recepción: 25 de junio del 2019

Fecha de aprobación: 5 de diciembre del 2019

\section{RESUMEN}

Este escrito tiene como objetivo abordar una pequeña muestra de la producción legislativa colombiana con el fin de exponer los distintos tipos de discriminación inmersos en las normas, acudiendo a una metodología para su clasificación y análisis que permita una observación más detenida del tratamiento positivo o negativo que le otorga la legislación vigente a un determinado grupo. En este caso, se trata de las mujeres con el fin de poner en evidencia la radiografía de nuestro ordenamiento jurídico frente al principio de igualdad que consigna la Carta política de 1991 .

Palabras clave: producción legislativa, enfoque de género, discriminación, derecho constitucional, derechos humanos, mujer.

El presente escrito es resultado del proyecto de investigación titulado "Derecho, Estado y Sociedad", del grupo de Derecho Público y TIC bajo la línea de investigación Derecho Constitucional y Políticas Públicas de la Universidad Católica de Colombia. Citar como González Cortés, G. L. (2020). ¿Perpetúan las normas la discriminación de las mujeres? De la necesidad del análisis de la producción legal en Colombia. Via Inveniendi et Iudicandi, 15(1), 119-160. Dor: https://doi.org/10.15332/19090528/5744

** Abogada de la Universidad Santo Tomás (Bogotá, Colombia) con maestría en Defensa de los Derechos Humanos y del Derecho Internacional Humanitario ante organismos, tribunales y cortes internacionales de la misma universidad. Docente de las universidades Santo Tomas (Bogotá, Colombia) y Católica de Colombia. glgonzalez@ucatolica.edu.co. orciD: https://orcid.org/0000-0002-3521-0425 
VIeI $\begin{aligned} & \text { Revista Virtual } \\ & \text { Via Inveniendi et Iudicandi }\end{aligned}$

\begin{abstract}
This paper aims to analyze a small sample of the Colombian legislative production in order to expose the different types of discrimination embedded in the norms. A methodology for their classification and analysis is used allowing a closer observation on the positive or negative treatment granted by the current legislation towards a specific human group. In this case, women are the ones taken into account exposing an $\mathrm{x}$-ray diagnosis of our legal system in the light of the principle of equality set out in the 1991 Colombian Political Constitution.
\end{abstract}

Key words: legislative production, gender perspective, discrimination, constitutional law, human rights, woman. 


\section{INTRODUCCIÓN}

Frente a un contexto que refleja en cifras contundentes y en aumento ${ }^{1}$ la práctica de violencia contra las mujeres en Colombia, cabe considerar el marco normativo de protección de sus derechos como punto de referencia y, por ende, de obligatoria observación.

Partiendo de la aún existente cosmovisión androcéntrica que permea nuestra sociedad en variados aspectos y de sus múltiples manifestaciones, incluso en la producción legal, es necesario revisar algunas de las leyes que conforman este marco con el fin de proponer un análisis desde una perspectiva constitucional con enfoque de género que permita dilucidar los diferentes tipos de discriminación inmersos en este tipo de fuentes de derecho.

Con tal objetivo se observa como centro de estudio la producción legal en Colombia en el periodo específico de 1992 a 2017. Se acude a una metodología de clasificación y análisis de las normas que permita identificar las que comparten determinadas características relevantes y así asimilarlas posteriormente dentro de un grupo, conforme al principio de igualdad del cual se deriva la prohibición de la discriminación. Esto da como resultado cuatro tipos de categorías de leyes que se exponen a continuación.

\section{TIPOS DE LEYES CONFORME EL PRINCIPIO DE IGUALDAD}

El principio de igualdad es la herencia de una tradición republicana que en varios siglos se ha consolidado en las constituciones modernas como elemento esencial de los ordenamientos jurídicos democráticos. Su importancia viene reforzada y complementada por la concepción de la dignidad humana inherente a cada individuo

1 En el informe Forensis elaborado por el Instituto de Medicina Legal en el 2017 se evidencia que el mayor porcentaje de homicidios ocurridos en el seno de la familia corresponde a conyugicidios $(55 \%)$, de los cuales el 79,12\% de las víctimas pertenece al género femenino. Sumado al dato anterior, el Instituto realiza en el mismo año 27.538 exámenes médico-legales por violencia intrafamiliar, de los que se concluye que las mujeres también son las mayores victimas (59,78\%). Finalmente, en relación con la violencia sexual, se resalta que en ese ańo se habría presentado el mayor número de casos registrados durante la última década, cuando el 85,4\% de las víctimas son las mujeres. 
sin que nadie sea más o menos importante frente a la ley. Estos postulados propios de un Estado liberal clásico, que pueden rastrearse en la inspiración ideológica de las revoluciones americana y francesa y en teóricos como John Locke y el barón de Montesquieu, partían de una igualdad formal, una especie de abstracción para imaginar a los seres humanos como sujetos homogéneos (Forero, 2014)

Por supuesto, este postulado pudo ser un razonamiento filosófico construido por convicción, pero, en su dimensión pragmática, se utilizó para oponerse al antiguo régimen político monárquico que sustentaba una jerarquía social de castas o niveles diferentes justificados por roles preestablecidos, tradición, religión y la fuerza armada.

Posteriormente, la igualdad de los hombres ante la ley propia de la ideología liberal es superada, entre otras razones, por las profundas contradicciones con la realidad frente a esa promulgada igualdad. Las condiciones sociales de ricos y pobres, propietarios y proletarios, niños y adultos, hombres y mujeres, blancos y negros, heterosexuales y homosexuales eran tan diferentes en los siglos XIX y xx, que el mismo modelo de Estado liberal debía ser reformado para superar las enormes tensiones generadas por las luchas sociales (Ballesteros, 2015).

La práctica del Estado liberal que intervenía mínimamente -el conocido en la doctrina como "estado gendarme" y con la recordada frase "dejar hacer, dejar pasar"-, además del aislamiento del estado soberano a escala internacional, que sostenía una barrera invisible ante la intromisión internacional, se modificó necesariamente ante los acontecimientos de la segunda guerra mundial. Surge un cataclismo de conciencia, no solo por el nivel de degradación de la guerra, sino también ante el riesgo que representaban las armas nucleares para la humanidad. En este escenario, y entendiendo que uno de los factores estructurales de la pasada guerra, así como de las futuras que se esperaba evitar, era la estratificación de los humanos en razas superiores e inferiores, grupos con y sin derechos, el principio de la igualdad entre las personas cobró una enorme relevancia.

Tan importante y urgente fue la necesidad de registrar y garantizar la igualdad, que en la Declaración Universal de Derechos Humanos, en su primer artículo, se contempla la igualdad de todos los seres humanos desde el momento de su nacimiento y, en el segundo, se establecería la titularidad del derecho a la igualdad a cada persona, sin 
que puedan ser discriminados por algún criterio diferenciador (Declaración universal de los derechos humanos, 1948). En sintonía, la Convención Americana sobre Derechos Humanos establecería el compromiso de los Estados parte de respetar los derechos de todas las personas sin diferenciación de ninguna índole (Convención Americana sobre Derechos Humanos, 1969).

Poco a poco, en un desarrollo que sigue en curso en nuestros días, la exigencia de intervenir a favor de ciertos grupos sociales más desventajados se ha venido concretando en resultados específicos, como los distintos tratados internacionales vinculantes para los Estados, exigibles en todo el mundo frente a órganos judiciales, normas jurídicas específicas para determinados grupos, jurisprudencias de tribunales nacionales que reiteran en casos concretos la tradicional protección a favor de ciertos individuos y los doctrinantes, que desde las distintas ciencias sociales han observado con atención todo el entramado que constituyen las relaciones sociales. Todos estos desarrollos son esfuerzos que se han sumado y han permitido el avance de la igualdad entre los individuos en la realidad: la denominada igualdad material que supera la concepción de igualdad formal (González, 2016)

En Colombia, la Constitución política de 1991 contempló, en el artículo 13, el principio de igualdad con una fórmula moderna de dimensión formal, pero asimismo material. El principio se expone en los siguientes tres párrafos:

Artículo 13. Todas las personas nacen libres e iguales ante la ley, recibirán la misma protección y trato de las autoridades y gozarán de los mismos derechos, libertades y oportunidades sin ninguna discriminación por razones de sexo, raza, origen nacional o familiar, lengua, religión, opinión política o filosófica.

El Estado promoverá las condiciones para que la igualdad sea real y efectiva y adoptará medidas en favor de grupos discriminados o marginados.

El Estado protegerá especialmente a aquellas personas que por su condición económica, física o mental, se encuentren en circunstancia de debilidad manifiesta y sancionará los abusos o maltratos que contra ellas se cometan. (Constitución Política de Colombia, 1991)

El primer párrafo se refiere a la prohibición de la discriminación de las personas, sin que se pueda diferenciar al momento de proteger o garantizar por parte de 
las autoridades sus derechos. Por su parte, los siguientes párrafos del artículo se refieren al deber del Estado de intervenir y beneficiar a determinados grupos sociales discriminados o en condiciones de debilidad manifiesta. Para Bernal (2008), el principio de igualdad se concreta en cuatro mandatos, que igualmente han sido reiterados por la jurisprudencia de la Corte Constitucional' ${ }^{2}$ :

(1) Mandato de trato idéntico a destinatarios que se encuentren en circunstancias idénticas; (2) un mandato de trato enteramente diferenciado a destinatarios cuyas situaciones no compartan ningún elemento común; (3) un mandato de trato paritario a destinatarios cuyas situaciones presenten similitudes y diferencias, pero las similitudes sean más relevantes que las diferencias (trato igual a pesar de la diferencia), y (4) un mandato de trato diferenciado a destinatarios que se encuentren también en una posición en parte similar y en parte diversa, pero en cuyo caso las diferencias sean más relevantes que las similitudes (trato diferente a pesar de la similitud). (Bernal Pulido, 2008)

Ahora bien, la clasificación en cuatro categorías de leyes que se propone en este documento parte de una simple división conforme al contenido del principio de igualdad. En primer lugar, la prohibición de la discriminación implica que es contrario a la Constitución o inconstitucional diferenciar de forma que se perjudique a una persona por criterios inherentes a su persona, como, por ejemplo, su sexo o, más específicamente, la condición de ser mujer. Este tipo de criterios no se encuentran justificados y, por tanto, se califican como discriminación negativa. Por el contrario, es constitucional discriminar o distinguir para beneficiar a este mismo grupo, con el objetivo de conseguir una mayor equidad. Se encuentra justificado diferenciar para brindar un trato preferente $\mathrm{y}$, en tal sentido, se califica de discriminación positiva. Por su parte, están las leyes que se manifiestan con un lenguaje expreso o explícito respecto de un grupo social, cuando de forma literal se hace referencia a ese grupo. A este tipo de leyes se refiere la calificación de discriminación directa. A contrario sensu, en otras ocasiones una ley no alude a un grupo en particular $y$, por tanto, se estructura

2 C 818 del 2010, C 250 del 2012 y C 015 del 2014 
un lenguaje neutro, pero de forma implícita se afecta un grupo determinado. A este último caso se refiere la calificación de discriminación indirecta.

Para analizar tendencias en la producción legislativa relativa a las mujeres en Colombia, por consiguiente, se acude a la clasificación de estas cuatro categorías: (1) leyes con discriminación positiva directa, (2) leyes con discriminación positiva indirecta, (3) leyes con discriminación negativa directa y (4) leyes con discriminación negativa indirecta.

El cuadro 1 representa el esquema de los tipos de discriminación hacia las mujeres, que, por supuesto, es aplicable a otros grupos vulnerables de la sociedad.

Cuadro 1. Tipos de discriminación hacia las mujeres

\section{(1) Discriminación positiva directa}

Se permite y promueve para garantizar equidad y condiciones económicas, sociales, laborales y más justas o para alcanzar una igualdad material.

\section{(2) Discriminación negativa directa}

Está expresamente prohibida por la Constitución política de 1991 y las disposiciones normativas que las contenían han sido persistentemente expulsadas del ordenamiento jurídico.

(4) Discriminación negativa indirecta No se menciona explícitamente en la Constitución, pero se deduce que está prohibida, como se ha mencionado en la jurisprudencia nacional e internacional, además de determinados tratados internacionales.

Partiendo de esta clasificación, a continuación, se describe de forma más amplia cada categoría y se citan algunas de las leyes expedidas por el Congreso de la República de Colombia en el periodo de 1992 hasta febrero del 2017, asignándolas a un tipo de ley específico.

\section{Leyes con discriminación positiva directa}

Mediante estas leyes se otorga un tratamiento diferencial a un grupo de sujetos determinados, con la finalidad de lograr una igualdad material. Su fundamento 
jurídico en Colombia se deriva de los incisos segundo y tercero del artículo 13, así como de los artículos 43 y 53 de la Constitución política, por lo cual se estructura el deber de proteger a las mujeres mediante un trato diferenciado y se puede calificar de privilegiado. Esta diferenciación, que se ha definido igualmente como discriminación inversa, se encuentra justificada, como lo ha reiterado el Tribunal Constitucional, para remediar o corregir las circunstancias de afectación de derechos de determinados grupos vulnerables, con el objetivo de alcanzar un orden justo conforme lo seńala el artículo segundo de la Carta política (Guarín, 2015).

La Corte Constitucional afirma al respecto que, dentro del Estado social de derecho, la cláusula de la igualdad tiene por objeto la protección de los grupos históricamente discriminados, y se expresa en una doble dimensión:

[...] por un lado, como mandato de abstención o interdicción de tratos discriminatorios (mandato de abstención) y, por el otro, como un mandato de intervención, a través del cual el Estado está obligado a realizar acciones tendientes a superar las condiciones de desigualdad material que enfrentan dichos grupos (mandato de intervención). (C. Constitucional, Sentencia T 291, 2009)

El reconocimiento de discriminaciones contra la mujer es el punto de partida para justificar la implementación de "medios adecuados" para corregir estas prácticas. Dentro de estos medios se tienen, entre otros, las leyes como generadoras de cambios sociales o formas de reiterar una costumbre aceptada.

Actualmente, es mayoritariamente aceptable el discurso antidiscriminación en Colombia, por lo cual existen diversas leyes que contienen de manera específica un tratamiento favorable para las mujeres. Si bien las leyes son un producto del Congreso de la República, es pertinente considerar la influencia de instrumentos internacionales que contienen compromisos para los Estados sobre la protección de la mujer. Estos van al unísono de las recomendaciones complementarias de organismos como la Convención sobre la Eliminación de Todas las Formas de Discriminación contra la Mujer (CEDAw, sigla en inglés) y de expertos como los relatores de la ONU, que han derivado en discriminaciones positivas que, en forma expresa, pretenden garantizar condiciones más favorables para las mujeres. 
En la misma Constitución política pueden encontrarse este tipo de tratamientos diferenciales. En el caso de la mujer se señala lo siguiente con respecto al derecho a participar en la conformación, ejercicio y control del poder político:

Acceder al desempeño de funciones y cargos públicos, salvo los colombianos, por nacimiento o por adopción, que tengan doble nacionalidad. La ley reglamentará esta excepción y determinará los casos a los cuales ha de aplicarse [...] Las autoridades garantizarán la adecuada y efectiva participación de la mujer en los niveles decisorios de la Administración Pública (itálicas fuera del texto). (Constitución, numeral 7 del artículo 40)

De la misma manera, el artículo 43 estipula, con relación al derecho a la igualdad:

La mujer y el hombre tienen iguales derechos y oportunidades. La mujer no podrá ser sometida a ninguna clase de discriminación. Durante el embarazo y después del parto gozará de especial asistencia y protección del Estado y recibirá de este subsidio alimentario si entonces estuviere desempleada o desamparada [...] El Estado apoyará de manera especial a la mujer cabeza de familia.

Con respecto a las leyes con discriminación positiva, a continuación, se enuncian las más pertinentes, expedidas en el periodo comprendido entre 1992 hasta febrero del 2017. No se incluyen las leyes por medio de las cuales se aprueban tratados internacionales sobre protección de derechos de la mujer, pues tienen origen foráneo 3 . La metodología consiste en citar la ley y sus principales tratos o medidas diferenciales a favor de la mujer, pero, así mismo, se determina la destinataria de la medida.

3 Se tienen en cuenta, por ejemplo, las siguientes leyes: la Ley 248 de 1995, por medio de la cual se aprueba la Convención Internacional para prevenir, sancionar y erradicar la violencia contra la mujer, suscrita en la ciudad de Belém do Pará, Brasil, el 9 de junio de 1994; la Ley 800 del 2003, por medio de la cual se aprueban la "Convención de las Naciones Unidas contra la Delincuencia Organizada Transnacional" y el "Protocolo para Prevenir, Reprimir y Sancionar la Trata de Personas, especialmente Mujeres y Niños, que complementa la Convención de las Naciones Unidas contra la Delincuencia Organizada Transnacional”, adoptados por la Asamblea General de las Naciones Unidas el 15 de noviembre del 2000; la Ley 984 del 2005, por medio de la cual se aprueba el "Protocolo facultativo de la Convención sobre la eliminación de todas las formas de discriminación contra la mujer”, adoptado por la Asamblea General de las Naciones Unidas el 6 de octubre de 1999. 
Sobre esta destinataria, se alude a los estereotipos de mujer que Facio (1992), precisa que deben advertirse al momento de analizar las normas jurídicas. Esta apreciación se comparte puesto que, dentro del grupo de leyes con discriminación positiva directa, la protección se dirige hacia la mujer, pero en diversos escenarios o contextos, como la mujer cabeza de familia, la mujer embarazada, la mujer víctima de violencia y, en ocasiones, la mujer en general.

Por consiguiente, una lectura crítica puede reconocer cómo la protección de la mujer cabeza de familia es un apoyo directo a la mujer, pero, igualmente, puede entenderse como el medio para proteger de forma indirecta a la familia o a los menores de edad. Las normas que se presentan a continuación representan un catálogo que busca una igualdad material entre mujeres y hombres, atendiendo sus particularidades y desventajas fácticas. Sin embargo, se resalta así mismo el estereotipo al cual va dirigida la ley de forma específica, $y$, al final de esta sección, se observa la frecuencia de protección de los siguientes tipos de mujer: mujer cabeza de familia, madre comunitaria, mujer persona, mujer embarazada, mujer víctima de violencia.

\section{Ley 82 de 1993}

\section{Modificada por la Ley 1232 del 2008}

Título: Por la cual se expiden normas para apoyar de manera especial a la mujer cabeza de familia.

Beneficiaria: mujer cabeza de hogar o de familia.

El artículo 2 la define como "quien siendo soltera o casada, ejerce la jefatura femenina de hogar y tiene bajo su cargo, afectiva, económica o socialmente, en forma permanente, hijos menores propios $\mathrm{u}$ otras personas incapaces o incapacitadas para trabajar, ya sea por ausencia permanente o incapacidad física, sensorial, psíquica o moral del cónyuge o compañero permanente o deficiencia sustancial de ayuda de los demás miembros del núcleo familiar".

\section{Principales tratos diferenciales}

- Afiliación de la mujer cabeza de familia y su familia al Sistema de Seguridad Social mediante las modalidades de pago a crédito y por excepción gratuita. 
- No se pueden negar los servicios de educación o salud de los hijos o personas dependientes de mujeres cabeza de familia.

- Atención preferente a solicitud de ingreso a educación primaria y secundaria de los hijos y dependientes.

- Capacitación gratuita y desarrollo de microempresas industriales, comerciales y artesanales.

- Estímulos especiales para el sector privado que adelante programas especiales de salud, educación, vivienda, seguridad social, crédito y empleo para las mujeres cabeza de familia.

- Especial atención por parte de entidades municipales o distritales de vivienda para asesorar a las mujeres cabeza de familia o que estas se asocien en organizaciones populares de vivienda (Ley 82, 1993).

\section{Ley 509 de 1999}

Modificada por la Ley 1023 del 2006; y esta última, a su vez, por la Ley 1187 del 2008

Título: Por la cual se disponen unos beneficios en favor de las madres comunitarias en materia de seguridad social y se otorga un subsidio pensional.

Beneficiarias: madres comunitarias (también se entiende incluidos hombres, aunque en la práctica son una excepción) y mujeres al cuidado de menores de edad.

Las madres comunitarias son las personas que prestan el servicio del cuidado de niños dentro del sistema de Hogares Comunitarios del Instituto Colombiano de Bienestar Familiar. Se cita la descripción oficial como sigue:

¿Quiénes son las madres comunitarias? Las madres o padres comunitarios son aquellos agentes educativos comunitarios responsables del cuidado de los niños y las niñas de primera infancia del programa de Hogares Comunitarios de Bienestar. Son reconocidos en su comunidad por su solidaridad, convivencia y compromiso con el desarrollo de los niños, niñas y sus familias. El Programa nace en el año 1986 y se reglamenta en 1989. (Instituto Colombiano de Bienestar Familiar. s.f.) 


\section{Principales tratos diferenciales}

- Las mujeres reciben prestaciones asistenciales y económicas del régimen contributivo de seguridad social previsto en la Ley 100 de 1993.

- Las mujeres reciben medidas especiales para formalizar su actividad laboral, puesto que se trata de personas de escasos recursos; por consiguiente, se les subsidia con el $80 \%$ los aportes a pensiones después de un año de prestación del servicio (Ley 509, 1999).

\section{Ley 581 del 2000}

Título: Por la cual se reglamenta la adecuada y efectiva participación de la mujer en los niveles decisorios de las diferentes ramas y órganos del poder público, de conformidad con los artículos 13, 40 y 43 de la Constitución Nacional y se dictan otras disposiciones.

Beneficiaria: mujer persona.

\section{Principales tratos diferenciales}

- Promoción de participación laboral femenina en el sector público, con el deber de satisfacer un porcentaje del $30 \%$ de los cargos de mayor jerarquía o de máximo nivel decisorio en las entidades de las tres ramas y órganos del poder público, en los diferentes entes territoriales.

- En cargos elegidos por ternas, debe incluirse por lo menos a una mujer; en los cargos elegidos por listas, deben incluirse hombres y mujeres en igual proporción.

- Medidas estatales para promover participación laboral femenina en el sector privado.

- Vigilancia del cumplimiento de la ley, especialmente con relación al principio de igual remuneración para trabajo igual (Ley 581, 2000). 


\section{Ley 731 del 2002}

Título: Por la cual se dictan normas para favorecer a las mujeres rurales.

Beneficiaria: mujer rural (mujer persona).

El artículo segundo de esta ley la define así: "Mujer rural es toda aquella que sin distingo de ninguna naturaleza e independientemente del lugar donde viva, su actividad productiva está relacionada directamente con lo rural, incluso si dicha actividad no es reconocida por los sistemas de información y medición del Estado o no es remunerada”.

\section{Principales tratos diferenciales}

- Deber de eliminar los obstáculos para que la mujer rural pueda acceder a beneficios que se otorguen para la actividad rural.

- Creación de cupos y créditos especiales con bajas tasas de interés.

- Creación del Fondo de Fomento para las mujeres rurales.

- Beneficios en seguridad social, subsidio familiar y afiliación al sistema de riesgos profesionales.

- Fomento de educación rural; el Sena debe crear programas de capacitación especiales.

- Participación equitativa en el Consejo Municipal de Desarrollo Rural y en los consejos territoriales de planeación (Ley 731, 2002).

\section{Ley 750 del 2002}

Título: Por la cual se expiden normas sobre el apoyo de manera especial, en materia de prisión domiciliaria y trabajo comunitario.

Beneficiaria: mujer cabeza de familia que esté cumpliendo pena privativa de su libertad. Se exceptúan las responsables de delitos graves como genocidio, homicidio o secuestro, entre otros, o que registren antecedentes penales. 


\section{Principales tratos diferenciales}

- La pena privativa de la libertad puede cumplirse en un lugar alternativo a un establecimiento penitenciario, como la residencia de la mujer cabeza de familia u otro que señale el juez.

- La mujer cabeza de familia puede realizar trabajos comunitarios de mantenimiento, aseo u obras públicas en perímetro urbano o rural, y el tiempo dedicado redimirá proporcionalmente la pena (Ley 750, 2002).

\section{Ley 790 del 2002}

Título: Por la cual se expiden disposiciones para adelantar el programa de renovación de la administración pública y se otorgan unas facultades extraordinarias al presidente de la República.

Beneficiaria: mujer cabeza de familia.

\section{Principales tratos diferenciales}

- El artículo 12 contempla una protección especial para las madres cabeza de familia sin alternativa económica, consistente en la prohibición del retiro del trabajo en desarrollo del Programa de Renovación de la Administración Pública. Mediante la Sentencia C174 del 2004, la Corte Constitucional declaró exequible este artículo de forma condicionada a que se incluyan los padres cabeza de familia en condiciones de igualdad (Ley 790, 2002).

\section{Ley 823 del 2003}

Título: Por la cual se dictan normas sobre igualdad de oportunidades para las mujeres.

Beneficiaria: mujer persona. 


\section{Principales tratos diferenciales}

Se trata de políticas públicas a favor de las mujeres que se ejercen a cargo del Estado, como las siguientes:

- Adoptar criterios de género en políticas, decisiones y acciones de todos los organismos públicos.

- Promover indicadores de género en la producción de estadísticas de organismos públicos y privados.

- Formular acciones y programas para prevenir discriminación de las mujeres en el trabajo.

- Mejorar el acceso de las mujeres a los servicios de salud integral, en especial niñas y adolescentes.

- Instaurar un programa de subsidio alimentario para las mujeres embarazadas que estén sin empleo.

- Garantizar el acceso a programas académicos en igualdad de condiciones para hombres y mujeres.

- Establecer créditos especiales para la compra de vivienda (Ley 823, 2003).

\section{Ley 861 del 2003}

Título: Por la cual se dictan disposiciones relativas al único bien inmueble urbano o rural perteneciente a la mujer cabeza de familia.

Beneficiaria: mujer cabeza de familia.

\section{Principales tratos diferenciales}

El único bien inmueble de propiedad de una mujer cabeza de familia se constituye en patrimonio de familia a favor de sus hijos menores de edad o por nacer y, en consecuencia, no puede ser embargado ni afectado por una medida cautelar. 
Mediante la Sentencia C 722 del 2004, se declara exequible la norma con la condición de que se extienda este beneficio a los hijos de padres cabeza de familia, no solo a las mujeres cabeza de familia (Ley 861, 2003).

\section{Ley 882 del 2004}

Título: Por medio de la cual se modifica el artículo 229 de la Ley 599 del 2000.

Beneficiaria: mujer víctima de violencia.

Trato diferencial: entre otras personas vulnerables, la agresión contra una mujer aumenta la pena privativa de la libertad en tres cuartas partes (Ley 882, 2004).

\section{Ley 1009 del 2006}

Título: Por medio de la cual se crea con carácter permanente el Observatorio de Asuntos de Género.

Beneficiaria: mujer en general, mujer persona.

Trato diferencial: se crea el Observatorio de Asuntos de Género cuyas funciones principales son documentar la situación de la mujer y la equidad de género. Este crea indicadores de género para abordar la reflexión crítica sobre las políticas que afectan a las mujeres y divulga información de género en el país y en el ámbito internacional (Ley 1009, 2006).

\section{Ley 1221 del 2008}

Título: Por la cual se establecen normas para promover y regular el teletrabajo y se dictan otras disposiciones.

Beneficiario: toda persona que pueda calificarse como teletrabajador. El artículo segundo lo define como la "persona que desempeña actividades laborales a través de tecnologías de la información y la comunicación por fuera de la empresa a la que presta sus servicios", (mujer cabeza de hogar). 
Trato diferencial: Promoción del teletrabajo a población vulnerable incluidas las mujeres cabeza de hogar conforme al parágrafo único del artículo tercero (Ley 1221, 2008).

\section{Ley 1257 del 2008}

Título: Por la cual se dictan normas de sensibilización, prevención y sanción de formas de violencia y discriminación contra las mujeres, se reforman los Códigos Penal, de Procedimiento Penal, la Ley 294 de 1996 y se dictan otras disposiciones.

Beneficiaria: mujer persona.

Trato diferencial: definición amplia de violencia de género como sigue y determinación de cada concepto:

Por violencia contra la mujer se entiende cualquier acción u omisión, que le cause muerte, daño o sufrimiento físico, sexual, psicológico, económico o patrimonial por su condición de mujer, así como las amenazas de tales actos, la coacción o la privación arbitraria de la libertad, bien sea que se presente en el ámbito público o en el privado. (Ley 1257 del 2008)

- Descripción de los derechos de las mujeres víctimas de violencia.

- Medidas de sensibilización y prevención en los ámbitos educativo, laboral, de salud, así como frente a la violencia contra las mujeres.

- Medidas de protección: posibilidad de denuncia de testigo de violencia intrafamiliar ante comisaria de familia, juez civil municipal o promiscuo.

- Procedimiento para prevenir la violencia intrafamiliar y en otros ámbitos diferentes.

- Sanciones como la prohibición de acercarse a la víctima o comunicarse con ella.

- Aumento de la pena por el delito de homicidio en persona protegida cuando se cometa contra una mujer, por el hecho de serlo (Ley 1257, 2008). 


\section{Ley 1413 del 2010}

Título: Por medio de la cual se regula la inclusión de la economía del cuidado en el sistema de cuentas nacionales con el objeto de medir la contribución de la mujer al desarrollo económico y social del país y como herramienta fundamental para la definición e implementación de políticas públicas.

Beneficiaria: mujer ama de casa: quien realiza actividades de trabajo del hogar.

Trato diferencial: se mide su contribución laboral no remunerada incorporándola en el sistema de cuentas nacionales. Se trata de una valoración y visibilización de este aporte con la finalidad de mejorar la percepción social de esta ocupación (Ley $1413,2010)$.

\section{Ley 1434 del 2011}

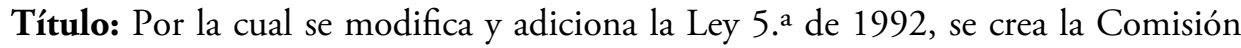
Legal para la Equidad de la Mujer del Congreso de la República de Colombia y se dictan otras disposiciones.

Beneficiaria: mujer persona.

\section{Tratamiento diferencial}

- Se crea una comisión legal en el Congreso de la república cuyo objetivo es la mejora de las circunstancias materiales e inmateriales de las mujeres en la sociedad.

- Principales funciones: elaborar propuestas legislativas sobre género, ejercer control político a entidades públicas, promover participación de la mujer en cargos de dirección y elección popular, hacer seguimiento a procesos de justicia transicional y desarrollar investigaciones de diversos entes de control relacionados con los derechos de las mujeres (Ley 1434, 2011).

\section{Ley 1468 del 2011}

Título: Por la cual se modifican los artículos 57, 58, 236 y 239 del Código Sustantivo del Trabajo y se dictan otras disposiciones. 
Beneficiaria: mujer embarazada.

\section{Tratamiento diferencial}

- Se amplía licencia de maternidad a 14 semanas en la época del parto (antes eran 12 semanas).

- Se prohíbe el despido por motivo del embarazo.

- La licencia de embarazo debe iniciar al menos una semana antes de la fecha probable del parto (Ley 1468, 2011).

\section{Ley 1475 del 2011}

Título: Por la cual se adoptan reglas de organización y funcionamiento de los partidos y movimientos políticos, de los procesos electorales y se dictan otras disposiciones.

Beneficiaria: mujer persona.

\section{Tratamiento diferencial}

- Se conforma equidad de género para participar en política.

- Se financian partidos políticos por parte del Estado con la regla de distribución del $5 \%$ según la proporción de mujeres en las corporaciones públicas.

- Se destinan recursos para los partidos políticos para que incluyan efectivamente mujeres, jóvenes y minorías étnicas (Ley 1475, 2011).

\section{Ley 1496 del 2011}

Título: Por medio de la cual se garantiza la igualdad salarial y de retribución laboral entre mujeres y hombres, se establecen mecanismos para erradicar cualquier forma de discriminación y se dictan otras disposiciones.

Beneficiaria: mujer persona. 


\section{Tratamiento diferencial}

- Se define la discriminación directa e indirecta en materia de retribución laboral por razón de género.

- Se obliga a las empresas de los sectores público y privado para que lleven registro de perfil y asignación de cargos por sexo, funciones y remuneración.

- Se instauran acciones y programas para garantizar que no haya discriminación de las mujeres en el trabajo (Ley 1496, 2011).

\section{Ley 1542 del 2012}

Título: Por la cual se reforma el artículo 74 de la Ley 906 del 2004, Código de Procedimiento Penal.

Beneficiaria: mujer víctima de violencia.

\section{Tratamiento diferencial}

- Cuando se conozcan hechos de violencia contra la mujer, las autoridades judiciales deben investigar de oficio, en cumplimiento de la obligación del Estado de actuar con debida diligencia para prevenir, investigar y sancionar la violencia contra las mujeres prevista en la Convención de Belém do Pará (Ley 1542, 2012).

\section{Ley 1761 del 2015}

Título: Por la cual se crea el tipo penal de feminicidio como delito autónomo y se dictan otras disposiciones (Rosa Elvira Cely).

Beneficiaria: mujer víctima de violencia.

\section{Tratamiento diferencial}

- Se crea el tipo penal del feminicidio como delito autónomo, por el cual se sanciona la violencia contra la mujer por motivos de género y discriminación. 
- El delito tiene una pena elevada, con diversas circunstancias de agravación especiales, y se excluyen los preacuerdos con una excepción.

- Inicio de investigación de oficio y el retiro de la denuncia por parte de la víctima no es determinante para archivar el proceso.

Para analizar desde la perspectiva de género la producción legal, es necesario evidenciar sobre qué concepción de mujer se ha legislado desde 1992 al 2017 en Colombia. El resultado que se presenta en el gráfico 1 permite observar una importante cantidad para las mujeres en general (8), seguidas por mujer cabeza de familia (5), madres comunitarias (2), mujer víctima (2), mujer embarazada (1), ama de casa (1) (Ley 1761, 2015).

Gráfico 1. Leyes por tipo de beneficiaria. Construcción propia

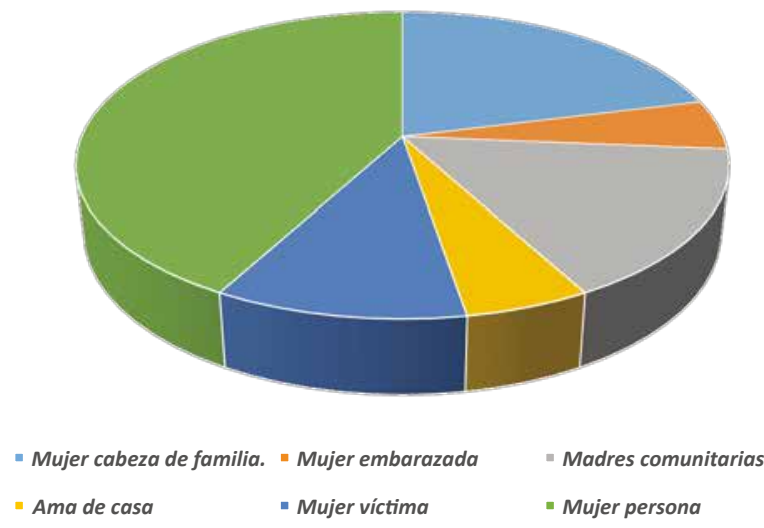

Fuente: elaboración del autor.

De acuerdo con Facio (1992), el derecho ha legislado de manera amplia sobre ciertos tipos de mujer, como, por ejemplo, la mujer madre o mujer familia y la mujer objeto sexual, pero muy poco sobre la mujer persona. Esto propicia la concepción errónea de protección de los derechos por medio de las leyes para "todas las mujeres" por igual $y$, por el contrario, sostiene de cierta manera la desigualdad con las otras.

No obstante, resulta interesante comparar este resultado del periodo de 1992 al 2017, con el análisis ya realizado en el periodo del 2002 al 2012 (González, 2016), 
por cuanto en este último la legislación de protección familiar fue más abundante. En el periodo más amplio de este documento, el espectro integró más leyes que protegían a la mujer persona, aunque esta a su vez pudiera subdividirse con mujer rural y mujer política.

En conclusión, en el periodo de tiempo analizado existe una equivalencia entre la legislación de la mujer en general y la mujer estereotipo de madre cabeza de familia, víctima de violencia o embarazada. Sin embargo, el resultado está más cerca del ideal de protección de derechos de la mujer sin estereotipos, al menos formalmente en las leyes analizadas.

\section{Leyes con discriminación positiva indirecta}

Estas leyes, como se advirtió antes, se caracterizan por dos razones: son positivas en la medida en que benefician a las mujeres y son indirectas, puesto que, en la literalidad de su texto, no se refieren directamente a las mujeres como grupo. No existe dentro del ordenamiento jurídico en Colombia ningún tipo de prohibición o exclusión de estas leyes, pero no solo la omisión de un pronunciamiento frente a ellas permite su existencia por el principio que se refiere a lagunas jurídicas como la de que "lo que no está prohibido está permitido". Si estas leyes contienen un beneficio en la práctica para las mujeres - concebidas como un grupo vulnerable al cual tanto el Estado como la sociedad deben proteger y garantizar sus derechos-, se deduce razonablemente que resulta permitido este efecto favorable de las leyes.

En cuanto a la deducción de este efecto favorable, es fácil para un operador de una ley concebir un beneficio indirecto para las mujeres cuando, por ejemplo, en una interpretación histórica se recurre a la exposición de motivos del proyecto de ley. En estos casos, la ley no contiene referencia alguna y puede utilizar un lenguaje neutro, pero puede, desde el proyecto de ley, formular una referencia literal para beneficiar sobre todo a las mujeres y motivar las necesidades derivadas de la realidad. Sin embargo, no son así todos los casos, puesto que el efecto indirecto de la ley es difícil de rastrear en ocasiones cuando ni la persona o personas que tuvieron la iniciativa legislativa, ni los congresistas que debatieron la ley previeron este efecto en la realidad. 
A continuación, se presentan algunas de las leyes que se considera que pueden clasificarse dentro de la categoría de discriminación positiva indirecta para las mujeres.

\section{Ley 294 de 1996}

Título: Por la cual se desarrolla el artículo 42 de la Constitución política y se dictan normas para prevenir, remediar y sancionar la violencia intrafamiliar.

Beneficiario: persona víctima de violencia intrafamiliar.

\section{Tratamiento diferencial indirecto}

La ley no se refiere específicamente a las mujeres como las beneficiadas con las medidas de protección estipuladas; sin embargo, es claro que las mayores víctimas de violencia intrafamiliar son y han sido las mujeres y, en mayor porcentaje, se trata deviolencia de pareja (Ley 294 de 1996). Según informe del 2013 del Instituto de Medicina Legal y Ciencias Forenses (INMLCF), el 87,21 \% de casos de violencia de pareja valorados (39020) correspondía a víctimas mujeres (INMLCF, 2013).

\section{Ley 311 de 1996}

Título: Por la cual se crea el Registro Nacional de Protección Familiar y se dictan otras disposiciones.

Beneficiario: hijos del padre que se abstenga de cumplir con la provisión de alimentos.

\section{Tratamiento diferenciado indirecto}

En el texto de la ley no se considera la mujer como beneficiada por esta ley. Sin embargo, la realidad de las relaciones de pareja en Colombia evidencia cómo, en la mayoría de los casos, el hombre es quien con mayor frecuencia incumple con su obligación de brindar alimentos para su hijo. En consecuencia, la mujer asume no solo la crianza del menor, sino que también debe asumir los gastos de su sostenimiento, educación y otros (Ley 311 de 1996). 
Por consiguiente, esta ley constituía un mecanismo legal para evitar este tipo de omisiones que, en la mayoría de los casos, atañe a los padres varones y, de esta forma, se garantizan los derechos de los hijos menores de edad o hijos adultos dependientes. Actualmente la ley se encuentra derogada.

\section{Ley 985 del 2005}

Título: Por medio de la cual se adoptan medidas contra la trata de personas y normas para la atención y protección de las víctimas de la misma.

Beneficiario: víctimas de trata de personas.

\section{Tratamiento diferencial indirecto}

El lenguaje es neutro y se refiere a las víctimas del delito de trata de personas, pero se encuentra plenamente documentado cómo, en su mayoría, las víctimas de este delito son mujeres y niñas en condiciones de pobreza o de desplazamiento, entre otros.

\section{Ley 1639 del 2013}

Título: Por medio de la cual se fortalecen las medidas de protección a la integridad de las víctimas de crímenes con ácido y se adiciona el artículo 113 de la Ley 599 del 2000 .

Beneficiario: víctimas de lesiones con ácido o sustancias similares.

\section{Tratamiento diferencial indirecto}

La ley utiliza un lenguaje neutro para referirse a las víctimas por ácido que pueden ser tanto hombres como mujeres. Sin embargo, la mayoría de los casos de víctimas de lesiones con ácidos son mujeres (Noticias RCN, 7 de enero del 2016), lo que se ha explicado conforme a un componente cultural como una forma de control sobre los cuerpos de ellas (Malaver, 2014). 


\section{Ley 1799 del 2016}

Título: Por medio de la cual se prohíben los procedimientos médicos y quirúrgicos estéticos para menores de edad y se dictan otras disposiciones.

Beneficiario: personas menores de 18 años.

\section{Tratamiento diferencial indirecto}

La ley es indirecta, puesto que en ningún momento utiliza lenguaje que permita deducir diferencia de sexo ni utiliza la expresión 'mujer' como la destinataria en ninguna de las disposiciones normativas. Sin embargo, se considera de discriminación positiva en tanto es un hecho fáctico que el mayor porcentaje de cirugías se les practican a mujeres y la norma busca proteger la salud de los menores de edad cuyos cuerpos aún no se hayan desarrollado totalmente, pues determinados tipos de cirugía puede afectarlos. Para brindar mayor claridad, en la respectiva exposición de motivos publicados en la Gaceta del Congreso (2015) se alude a los riesgos tanto físicos como psicológicos de cirugías realizadas a mujeres, así como el alto porcentaje de mujeres menores de edad que buscan anticiparse con las cirugías a un modelo sexual adulto (Ley 1799, 2016).

\section{Leyes con discriminación negativa directa}

Esta categoría se refiere a leyes que contienen un tratamiento diferencial que afecta a las mujeres, con la particularidad semejante a las leyes con discriminación positiva directa de ser explícitas. Es decir, las leyes contienen una fórmula gramatical que alude directamente a las mujeres para darles un tratamiento distinto al de los hombres o contiene una fórmula en que el sujeto de la disposición son los hombres o los varones como titulares de una potestad o derecho como criterio excluyente.

Como ya se ha advertido, a partir de la doble dimensión del derecho surgen para el Estado diversos deberes, de los cuales pueden ubicarse estas leyes en el mandato de abstención; por ello, la Corte Constitucional resalta que

[...] existe un deber de la administración de abstenerse de adelantar, promover o ejecutar políticas, programas o medidas que conduzcan a agravar o perpetuar 
la situación de exclusión, marginamiento o discriminación de grupos tradicionalmente desventajados en la sociedad. Esto se deriva principalmente de la cláusula de igualdad formal y del principio de no discriminación establecido en el inciso primero del artículo 13. (Sentencia T-291, 2009)

Estas manifestaciones se han eliminado en Colombia del ordenamien to jurídico como resultado de muchos factores. Entre ellos, se encuentran los argumentos basados en criterios lógicos que desmitifican costumbres, por parte de las luchas sociales, las manifestaciones políticas con creciente participación de las mujeres y, recientemente, con los compromisos internacionales que adquirió el Estado colombiano para eliminar la discriminación contra la mujer.

Estos cambios conllevaron a que, para el periodo estudiado, la labor de los congresistas estuviera condicionada por lo que podría denominarse discursos socialmente aceptados y otros no aceptados. Entre estos últimos, se encuentra un discurso patriarcal que concibe ciertas características de las mujeres como si fueran dadas por su naturaleza o por tradiciones impuestas por la religión o la moral, entre otras razones que justificaban un tratamiento legal diferente.

En forma análoga, ha existido desconfianza en la actividad legislativa en Colombia, en contraste con los sistemas legales en otras latitudes, circunstancia que condicionó el modelo de Estado de la Constitución de 1991. Esta afirmación puede comprobarse una vez se observan los controles previstos durante el trámite de la ley y con posterioridad a su expedición, que no son propios del debate legislativo, sino de las otras ramas del poder y de la misma participación política de los ciudadanos. Figuras como la objeción presidencial (art. 165 C. P.), la acción pública de constitucionalidad (n. ${ }^{\circ}$ 6, art. 40 C. P.), la excepción de inconstitucionalidad (art. 4 C. P.) constituyen un robusto modelo de control de las leyes cuya consecuencia es la desaparición de discriminaciones negativas.

Lo expuesto es de suma importancia para explicar cómo este tipo de leyes discriminatorias hacia las mujeres no solo eran acatadas, sino defendidas, como condición del bienestar de la sociedad mediante la conservación de un modelo familiar idealizado y que hoy en día, como ya se ha dicho, no son socialmente aceptables y, por ende, escasean en el ordenamiento jurídico en observación. 
Esto obedecerá, primero que todo, a que por ser leyes abiertamente inconstitucionales, tan solo aplicadas una interpretación exegética son identificables con facilidad mediante los controles que evitan su irrupción dentro del sistema legal. Además, porque ese discurso en la sociedad colombiana de la primera década del siglo Xxi no es aceptable, lo que conduce a que se presente una impopularidad general a quien sostenga una disertación con ese talante discriminatorio. En consecuencia, dentro de los debates legislativos, los argumentos que antaño podían sustentar este tipo de leyes no tendrían aprobación mayoritaria. Se advierte aún más que un congresista que exteriorice dentro de los respectivos debates legislativos razones discriminatorias contra las mujeres es, a su vez, discriminado por la censura general.

Por otra parte, debe resaltarse cómo, a través del ejercicio de la acción de inconstitucionalidad prevista en el artículo 241 superior y reglamentada en el Decreto 2067 de 1991, la Corte Constitucional de Colombia ha tenido oportunidad de estudiar y expulsar paulatinamente del ordenamiento jurídico ciertas expresiones que contienen referencias directas al sexo femenino, de tal forma que se ha realizado una progresiva depuración del ordenamiento jurídico para que se mantenga en coherencia con los postulados axiológicos de la Constitución política.

De este modo, la jurisprudencia de la Corte Constitucional, al igual que otros tribunales de justicia constitucional en el mundo a partir de las sentencias de la Corte Suprema de Justicia de los Estados Unidos, han consolidado como herramienta hermenéutica para valorar posibles afectaciones al principio de igualdad los denominados criterios o categorías sospechosas, que son potencialmente discriminatorias, como, por ejemplo,

[...] aquellas diferenciaciones (1) que se fundan en rasgos permanentes de las personas, de las cuales estas no pueden prescindir por voluntad propia, a riesgo de perder su identidad; además (2) esas características han estado sometidas, históricamente, a patrones de valoración cultural que tienden a menospreciarlas; en tercer término, esos puntos de vista (3) no constituyen, per se, criterios con base en los cuales sea posible efectuar una distribución o reparto racionales y equitativos de bienes, derechos o cargas sociales. Finalmente, (4) en otras decisiones, esta corporación ha también indicado que los criterios indicados en el artículo 13 superior también deben ser considerados sospechosos, no solo por cuanto se encuentran explícitamente señalados por el texto constitucional, 
sino también porque han estado históricamente asociados a prácticas discriminatorias. (Sentencia C-481, 1998)

Por consiguiente, en el periodo estudiado de 1992 hasta febrero del 2017, son muy escasas las leyes con discriminación directa contra las mujeres; esto se une a que el alto tribunal ha declarado inconstitucionales normas que contenían estas expresiones, pero existían con anterioridad a la promulgación de la vigente Constitución política de 1991, como son el Código Civil aún vigente, la Ley 57 de 1887, el Código Sustantivo del Trabajo y el Decreto Ley 3743 de 1950, entre otros. A continuación, se exponen algunos ejemplos de providencias para ilustrar lo mencionado y procurar de forma concreta citar las principales razones de la decisión.

\section{Sentencia C-622 del 1997}

Se presentó acción de inconstitucionalidad contra el artículo 242 del Código Sustantivo del Trabajo, modificado por el Decreto 13 de 1967, referente a los trabajos prohibidos y, en particular, se estableció la prohibición, para todas las empresas, de emplear mujeres durante la noche, salvo que se trate de una empresa integrada por miembros de una misma familia.

La Corte declaró la citada norma inexequible porque encontró, a partir de los principios constitucionales y, en especial, de los artículos 13 y 43 que no es razonable ni justificable impedir que una mujer pueda laborar durante la noche en las mismas condiciones que los hombres. Así, actualmente tanto las mujeres como los hombres pueden participar en igualdad de oportunidades en procesos laborales, económicos, sociales y demás, a diferencia de siglos pasados cuando se idealizaba a las mujeres como sujetos débiles, vulnerables y dependientes que necesitaban una especie de protección paternalista. En palabras del tribunal constitucional:

Lejos de considerarse una norma protectora, el precepto acusado tiene un carácter paternalista y conduce a prohibir que las mujeres puedan laborar durante la noche, en las empresas industriales, lo cual constituye una abierta discriminación contra ella, que debe ser abolida, pues aparte de tener plena capacidad para el trabajo en condiciones dignas y justas, debe garantizárseles en igualdad de condiciones con los hombres, el ejercicio 
de los mismos derechos y oportunidades que se requieran, para que ellas, dentro de la protección requerida, puedan trabajar en la jornada nocturna.

\section{Sentencia C-112 del 2000}

Se presentó acción de inconstitucionalidad contra el artículo 126 del código civil modificado por el artículo 7 del Decreto 2272 de 1989, que determinaba que el matrimonio se celebrara ante el juez del distrito de la vecindad de la mujer. A juicio de la Corte, este criterio se consideró violatorio del principio de igualdad, razón por la cual declaró inexequible la expresión “de la mujer”.

El razonamiento que fundamentó su decisión consiste en que se trata de una categoría sospechosa que, en principio, está prohibida y, por ende, se presumen inconstitucionales, a menos que exista una motivación válida que motive su uso. No obstante, señalan que la misma Corte o "corporación no encontró ninguna razón suficientemente convincente, ni explícita, ni implícita, que pudiera justificar esa decisión legislativa”. De igual modo, justificó la oportunidad de analizar el artículo 131 del mismo Código Civil a partir de la figura de la unidad normativa, con la cual el artículo 126 tenía directa relación.

\section{Sentencia C-007 del 2001}

Se estudió la inconstitucionalidad del numeral 6 del artículo 140 del Código Civil, referente a una de las causales de nulidad del matrimonio, cuando no existiera libertad en el consentimiento de la mujer raptada violentamente, pero se exceptuaba de esta nulidad si se otorgaba el consentimiento posteriormente fuera del poder del captor.

Parte del principio de hermenéutica constitucional de conservación del derecho según el cual si, a partir de una disposición existen varias interpretaciones y al menos una es constitucional, debe preservar la norma, pero retirar la lectura inconstitucional. Así es como se declara exequible la norma, siempre que no se excluya a los hombres puesto que no se encontró justificación por la cual el hombre igualmente no pudiera ser víctima de un secuestro con móvil nupcial y, posteriormente convalidar la unión con su consentimiento. En este caso, se trató de una discriminación directa contra el hombre por cuanto no se trata de una expresión neutra, a partir de la categoría mujer. 


\section{Sentencia C-804 del 2006}

Estudio la acción de inconstitucionalidad contra el artículo 33 de código civil, que contiene una aclaración en el uso del lenguaje del ordenamiento jurídico, por cuanto las palabras hombres, niños, adulto y otras semejantes debían comprenderse como si abarcaran a las personas de ambos sexos; por el contrario, las palabras mujeres, niñas, viuda no incluiría el sexo masculino.

En la consideración jurídica 8, intitulada "Las situaciones de inclusión o exclusión también se proyectan en el lenguaje jurídico. La razón patriarcal y su proyección en el lenguaje jurídico y en la cultura jurídica", la Corte da cuenta de cómo los valores sociales se plasman en las normas, y concluye:

No es extraño, por consiguiente, que la situación de invisibilidad, subordinación, y discriminación a la cual por largos años se vieron y se han visto sometidas las mujeres, se proyectara también en el modo en que se fijaron los criterios de inclusión y exclusión mediante el lenguaje jurídico generando, de paso, una cultura de tipo patriarcal que se proyectó y, aún se proyecta, en el lenguaje jurídico y en la cultura jurídica. (Corte Constitucional, 2009)

De este modo, el artículo 33 del Código Civil fue declarado inexequible porque se concibió como una manifestación de la ideología de la supremacía masculina. Pero puesto que el lenguaje jurídico es fruto de las costumbres sociales y, de forma paralela, modifica la realidad, no puede ser indiferente a la protección de los derechos de la mujer, así como la coherencia con la Carta política. En otras palabras, reproducir un lenguaje sexista equivale a desconocer la dignidad de las mujeres y sus derechos.

De acuerdo con lo anterior, toda y cualquier distinción -incluso diferenciaciones lingüísticas basadas en el sexo-que desconozcan o amenacen desconocer el goce y ejercicio de los derechos de las mujeres debe ser rechazada por lo menos en el ámbito jurídico. (Corte Constitucional, 2009)

Finalmente, como ejemplo de las escasas leyes con discriminación directa expedidas con posterioridad a la entrada en vigencia de la Constitución de 1991, se cita el siguiente: 
Ley 48 de 1993, por la cual se reglamenta el servicio de reclutamiento y movilización. Mediante acción de inconstitucionalidad, se demandó parcialmente el texto resaltado del parágrafo único del artículo 10:

Artículo 10. Obligación de definir la situación militar. Todo varón colombiano está obligado a definir su situación militar a partir de la fecha en que cumpla su mayoría de edad, a excepción de los estudiantes de bachillerato, quienes definirán cuando obtengan su título de bachiller. La obligación militar de los colombianos termina el día en que cumplan los cincuenta (50) años de edad.

Parágrafo. La mujer colombiana prestará el servicio militar voluntario, y será obligatorio cuando las circunstancias del país lo exijan y el Gobierno Nacional lo determine, en tareas de apoyo logístico, administrativo, social, cultural o de defensa de la ecología y el medio ambiente, y en general, de las actividades que contribuyan a la modernización y al desarrollo del país y tendrán derecho a los estímulos y prerrogativas que establece esta Ley no importando la modalidad en que se preste el servicio.

Según la Sentencia C-659 del 2016, la Corte Constitucional declaró inconstitucional el texto, puesto que se trata de una infracción a la prohibición de discriminación y trato distinto no justificado por razones de sexo. La asignación de tareas para las mujeres que son de apoyo para las que son propiamente militares, reservadas exclusivamente a los hombres, es el resultado de estereotipos de inferioridad de la mujer y supuestas capacidades limitadas. Así mismo, no son la ley ni la jurisprudencia la que deben determinar los oficios aptos para las mujeres, lo que depende de una decisión autónoma y personal de cada mujer ${ }^{4}$.

\section{Leyes con discriminación negativa indirecta}

Esta categoría está integrada por leyes que utilizan un lenguaje neutral, no se refieren en su texto propiamente al grupo mujeres, pero, no obstante, implican en la práctica un tratamiento negativo para aquellas. La Convención sobre la Eliminación de Todas

4 Véase el Comunicado de prensa n. ${ }^{\circ} 50$ del 28 de noviembre del 2016 de la Corte Constitucional (al momento de elaborar este artículo no se había publicado la sentencia). 
las Formas de Discriminación contra la Mujer (CEDAw) incluye una definición muy genérica en su artículo primero acerca de la discriminación contra la mujer:

[...] toda distinción, exclusión a restricción basada en el sexo que tenga por objeto o por resultado menoscabar o anular el reconocimiento, goce o ejercicio por la mujer, independientemente de su estado civil, sobre la base de la igualdad del hombre y la mujer, de los derechos humanos y las libertades fundamentales en las esferas política, económica, social, cultural y civil o en cualquier otra esfera (énfasis añadido). (CEDAw, 1979)

Precisamente una de las características principales de la discriminación negativa indirecta, aparte de su lenguaje neutro, es que su existencia se figura en el resultado, en la práctica, en la realidad. En el caso particular de las leyes jurídicas, puede que su texto sea genérico, pero deriva en consecuencias fácticas negativas para determinados sujetos. Este elemento hace, por ejemplo, que un legislador, juez o alcalde no advierta a primera vista estas consecuencias. El factor de intencionalidad para afectar a un grupo no es significativo, su elemento volitivo, con la dificultad probatoria que esto implica, no es necesario. Lo importante es verificar su aplicación en la realidad, su resultado.

El Comité de Expertos de la CeDaw presentó la Recomendación General n. ${ }^{\circ} 25$ mediante la cual, una vez interpretados sistemáticamente los artículos $10^{\circ}$ a $50^{\circ}$ y 24 de la Convención, concluyó que se derivan tres obligaciones para los Estados parte, de los cuales nos interesa el numeral 7 del acápite II, Antecedentes: objeto y fin de la Convención:

[...] garantizar que no haya discriminación directa ni indirecta contra la mujer en las leyes y que, en el ámbito público y el privado, la mujer esté protegida contra la discriminación — que puedan cometer las autoridades públicas, los jueces, las organizaciones, las empresas o los particulares- por tribunales competentes y por la existencia de sanciones y otras formas de reparación. (CEDAW, 2004)

En el mismo documento, el Comité señala lo que debe entenderse por discriminación indirecta con el siguiente tenor: 
Puede haber discriminación indirecta contra la mujer cuando las leyes, las políticas y los programas se basan en criterios que aparentemente son neutros desde el punto de vista del género pero que, de hecho, repercuten negativamente en la mujer. Las leyes, las políticas y los programas que son neutros desde el punto de vista del género pueden, sin proponérselo, perpetuar las consecuencias de la discriminación pasada. Pueden elaborarse tomando como ejemplo, de manera inadvertida, estilos de vida masculinos y así no tener en cuenta aspectos de la vida de la mujer que pueden diferir de los del hombre. Estas diferencias pueden existir como consecuencia de expectativas, actitudes y comportamientos estereotípicos hacia la mujer que se basan en las diferencias biológicas entre los sexos. También pueden deberse a la subordinación generalizada de la mujer al hombre . (CEDAw, 2004)

Esa verificación en la práctica implica que una ley en apariencia no discriminatoria en el texto, al llevarla a la práctica, ocasiona un tratamiento desfavorable a las mujeres sin justificación. Por ende, la simple interpretación de la ley dentro del derecho no es suficiente, lo que implica que no se pueden comprobar de forma directa.

Un caso de este tipo de leyes se evidencia en la Sentencia C-754 del 2015, en la que la Corte Constitucional se manifestó respecto de la existencia de discriminación indirecta del artículo 23 de la Ley 1719 del 2014. El artículo se refiere a la atención integral y gratuita para las víctimas de violencia sexual y, de forma específica, la acción de inconstitucionalidad se presentó contra la palabra facultad, por cuanto, según el artículo, las entidades del sistema de salud

\section{[...] están en la facultad de implementar el Protocolo y el Modelo de Atención Integral en Salud para las Víctimas de Violencia Sexual, que contendrá dentro de los procedimientos de interrupción voluntaria del embarazo la objeción de los médicos y la asesoría de la mujer en continuar o interrumpir el embarazo. (Corte Constitucional, 2015)}

5 En el vigésimo periodo de sesiones de 1999, sobre el párrafo 1 del artículo 4. ${ }^{\circ}$ de la Convención sobre la Eliminación de Todas las Formas de Discriminación contra la Mujer, referente a medidas especiales de carácter temporal, disponible en: http://www.un.org/womenwatch/daw/cedaw/recommendations/General\%20 recommendation $\% 2025 \% 20$ (Spanish).pdf. 
Para la Corte existe una discriminación indirecta derivada de la disposición, por cuanto, si bien a primera vista se observa un contenido neutro, pues se refiere en general a las víctimas de violencia sexual, se produce un impacto mayor sobre las mujeres y, sobre todo, en el contexto del conflicto armado. Esta afirmación se sustenta en estadísticas del Ministerio de Salud y Protección Social y el Instituto de Medicina Legal y Ciencias Forenses, además del Auto 092 del 2008, en el que se revisaron las afectaciones a los derechos fundamentales de las víctimas de violencia sexual. Así se concluye en la providencia:

De acuerdo con lo anterior, la expresión "facultad" del artículo 23 de la Ley 1719 del 2014, al determinar condiciones de desigualdad en la accesibilidad a los servicios de salud de las víctimas de violencia sexual y tener un impacto indirecto y desproporcionado en las mujeres, y en un mayor grado en la población de mujeres parte de grupos vulnerables, genera una discriminación indirecta e interseccional, que hace que la norma sea inconstitucional por violación a los artículos 13, 49 y del bloque de constitucionalidad. (Corte Constitucional, 2009)

Igualmente, es posible integrar la categoría de discriminación negativa indirecta la norma contenida en la Ley 972 del 2005, que se expone a continuación.

\section{Ley 972 del 2005}

Título: Por la cual se adoptan normas para mejorar la atención por parte del Estado colombiano de la población que padece de enfermedades ruinosas o catastróficas, especialmente el $\mathrm{vIH} /$ sida.

Beneficiarios: personas contagiadas con $\mathrm{VIH} /$ sida.

\section{Tratamiento negativo indirecto}

Los hombres y mujeres que tengan en su organismo la infección del síndrome de inmunodeficiencia adquirida (sida), son beneficiados con esta ley que implementa de forma concreta obligaciones de las entidades que conforman el Sistema General de Seguridad Social en Salud. No obstante, existe una clara diferencia biológica entre 
un hombre y una mujer que se encuentre en estado de embarazo, puesto que no todos los medicamentos que consumen los enfermos de viH, en general, les sirven a estas mujeres. Esto obedece a que en ciertos casos estos medicamentos pueden tener efectos secundarios que afectan tanto la salud de la madre como la de su hijo. En la citada ley no existe ninguna referencia a las madres gestantes con VIH, quienes, por demás, deben recibir un tratamiento diferente y especializado ${ }^{6}$.

\section{Conclusiones}

El análisis de la legislación en Colombia durante la vigencia de la actual Constitución Política de 1991, del periodo entre 1992 y febrero del 2017, mediante las citadas cuatro categorías, permitió observar diversos usos de las leyes conforme al principio de igualdad del cual se deriva la prohibición de discriminación. Como se ha señalado, está prohibido discriminar a un grupo de individuos de forma injustificada. Por el contrario, está permitido - y aún es una obligación legal para el Estado de Colombia - discriminar de forma positiva o, en otras palabras, brindar un trato benéfico a ciertos individuos que han sido históricamente discriminados, como son las mujeres, lo que, en tal sentido, se encuentra justificado.

En las categorías de discriminación positiva directa para el grupo mujeres se identificó un número de 19 leyes, en las cuales se identificaron diversos roles sociales que caracterizan el perfil de la mujer que el legislador ha procurado proteger. Por demás, estas leyes constituyen no solo la herencia universal de las mujeres y sus luchas en todo el mundo, sino que también son conquistas locales que se han logrado con no pocos obstáculos y, a veces, como efecto detonante por el clamor de una sociedad ante hechos que se pretenden prevenir para que no vuelvan a ocurrir. Son ejemplos el abominable homicidio de Rosa Elvira $\mathrm{Cely}^{7}$ o la agresión contra Natalia Ponce

6 Véase Medicamentos contra el ViH durante el embarazo y parto. (InfoSIDA, 9 de marzo del 2017).

7 Rosa Elvira Cely fue una mujer de 35 años que fue víctima de abuso sexual y graves lesiones personales por parte de un compańero de su colegio en la jornada nocturna, Javier Velasco, en un parque público de Bogotá el 24 de mayo del 2012. Falleció después de permanecer varios días en un hospital como consecuencia de las heridas ocasionadas en su cuerpo. Estos hechos originaron la expedición de la Ley 1761 del 2015 por la cual se crea el tipo penal del feminicidio. 
de León ${ }^{8}$, así como su valiente lucha, víctimas visibles de la violencia de género que sufren cientos de mujeres en el país. Ellas forman parte de las estadísticas que desdicen de nuestra sociedad o que, aún peor, se encuentran hoy presas en el silencio que no les permite denunciar.

Igualmente, las leyes con discriminación positiva indirecta son una categoría desconocida pero existente en la legislación, con al menos cinco casos que puede servir como herramienta para beneficiar a las mujeres en mayor porcentaje, sin que se excluya totalmente a los hombres.

Porsu parte, las leyes con discriminación negativa indirectason fácilmenteidentificables por cuanto son explícitas y utilizan categorías sospechosas, como la referencia a ciertos grupos vulnerables. Por consiguiente, el control de constitucionalidad ha sido un mecanismo muy importante, así como los mismos debates parlamentarios, para excluir cualquier tipo de leyes o disposiciones de este orden.

Por el contrario, las leyes con discriminación negativa indirecta, como se ha reiterado, son difíciles de identificar a primera vista. El lenguaje neutro, la irrelevancia ante una intención del legislador y la importancia de la discriminación en el resultado hacen que una ley pueda constituir una discriminación negativa indirecta no de forma inmediata, sino con posterioridad y por los cambios sociales. En otras palabras, una ley neutra puede propiciar las condiciones para que posteriormente se constituyan desventajas para un grupo vulnerable, como las mujeres, lo que podría calificarse como una discriminación sobreviniente.

Finalmente, la revisión de las leyes en cuestión mediante las categorías propuestas que contienen las distintas discriminaciones como herramienta hermenéutica permite una observación más detenida del tratamiento positivo o negativo que le otorga la legislación vigente a un determinado grupo, en este caso, las mujeres, poniendo en evidencia la radiografía de nuestro ordenamiento jurídico frente al principio de igualdad del que reza la Carta política de 1991.

8 Natalia Ponce de León es una víctima de violencia de género que fue atacada con ácido el 24 de marzo del 2014 por parte de Jonathan Vega. Estos hechos motivaron la expedición de la Ley 1773 del 2016, referente a lesiones con agentes químicos. 


\section{NORMAS JURÍDICAS}

Congreso Nacional de la República (3 de noviembre de 1993). Ley 82 del 3 de noviembre de 1993, por la cual se expiden normas para apoyar de manera especial a la mujer cabeza de familia. Diario Oficial, n. ${ }^{\circ}$ 41.101, 3 de noviembre de 1993, Bogotá.

Congreso Nacional de la República (1999, 30 de julio). Ley 509 de 1999, por la cual se disponen unos beneficios en favor de las Madres Comunitarias en materia de Seguridad Social y se otorga un Subsidio Pensional. Diario Oficial, n. * 43.653, 3 de agosto de 1999, Bogotá.

Congreso Nacional de la República (31 de mayo del 2000). Ley 581 del 2000, por la cual se reglamenta la adecuada y efectiva participación de la mujer en los niveles decisorios de las diferentes ramas y órganos del poder público, de conformidad con los artículos 13, 40 y 43 de la Constitución Nacional y se dictan otras disposiciones. Diario Oficial, n. ${ }^{\circ}$ 44.026, 31 de mayo del 2000, Bogotá.

Congreso Nacional de la República (14 de enero del 2002). Ley 731 del 2002, por la cual se dictan normas para favorecer a las mujeres rurales. Diario Oficial, n. ${ }^{\circ} 44.678,16$ de enero del 2002, Bogotá.

Congreso Nacional de la República (19 de julio del 2002). Ley 750 del 2002, por la cual se expiden normas sobre el apoyo de manera especial, en materia de prisión domiciliaria y trabajo comunitario. Diario Oficial, n.o 44.872, 19 de julio del 2002, Bogotá.

Congreso Nacional de la República (27 de diciembre del 2002). Ley 790 del 2002, por la cual se expiden disposiciones para adelantar el programa de renovación de la administración pública y se otorgan unas facultades extraordinarias al presidente de la República. Diario Oficial, n. ${ }^{\circ}$ 45.046, 27 de diciembre del 2002, Bogotá

Congreso Nacional de la República (10 de julio del 2003). Ley 823 del 2003, por la cual se dictan normas sobre igualdad de oportunidades para las mujeres. Diario Oficial, n. ${ }^{\circ}$ 45.245, 11 de julio del 2003, Bogotá.

Congreso Nacional de la República (26 de diciembre del 2003). Ley 861 del 2003, por la cual se dictan disposiciones relativas al único bien inmueble urbano o rural perteneciente a la mujer cabeza de familia. Diario Oficial, n. ${ }^{\circ} 45.415,29$ de diciembre del 2003, Bogotá.

Congreso Nacional de la República (2 de junio del 2004). Ley 882 del 2004, por medio de la cual se modifica el artículo 229 de la Ley 599 del 2000. Diario Oficial, n. ${ }^{o} 45.568,3$ de junio del 2004, Bogotá. 
Congreso Nacional de la República (23 de enero del 2006). Ley 1009 del 2006, por medio de la cual se crea con carácter permanente el Observatorio de Asuntos de Género. Diario Oficial, n. ${ }^{\circ}$ 46.160, 23 de enero del 2006, Bogotá.

Congreso Nacional de la República (16 de julio del 2008). Ley 1221 del 2008, por la cual se establecen normas para promover y regular el Teletrabajo y se dictan otras disposiciones. Diario Oficial, n. ${ }^{\circ}$ 47.052, 16 de julio del 2008, Bogotá.

Congreso Nacional de la República (4 de diciembre del 2008). Ley 1257 del 2008, por la cual se dictan normas de sensibilización, prevención y sanción de formas de violencia y discriminación contra las mujeres, se reforman los Códigos Penal, de Procedimiento Penal, la Ley 294 de 1996 y se dictan otras disposiciones. Diario Oficial, n. ${ }^{\circ}$ 47.193, 4 de diciembre del 2008, Bogotá.

Congreso Nacional de la República (11 de noviembre del 2010). Ley 1413 del 2010, por medio de la cual se regula la inclusión de la economía del cuidado en el sistema de cuentas nacionales con el objeto de medir la contribución de la mujer al desarrollo económico y social del país y como herramienta fundamental para la definición e implementación de políticas públicas. Diario Oficial, n. ${ }^{\circ}$ 47.890, 11 de noviembre del 2010, Bogotá.

Congreso Nacional de la República (6 de enero del 2011). Ley 1434 del 2011, por la cual se modifica y adiciona la Ley 5 a $^{\text {a }}$ e 1992, se crea la Comisión Legal para la Equidad de la Mujer del Congreso de la República de Colombia y se dictan otras disposiciones. Diario Oficial, n. ${ }^{\circ}$ 47.944, 6 de enero del 2011, Bogotá.

Congreso Nacional de la República (30 de junio del 2011). Ley 1468 del 2011, por la cual se modifican los artículos 236, 239, 57, 58 del Código Sustantivo del Trabajo y se dictan otras disposiciones. Diario Oficial, n. ${ }^{o} 48.116,30$ de junio del 2011, Bogotá.

Congreso Nacional de la República (14 de julio del 2011). Ley 1475 del 2011, por la cual se adoptan reglas de organización y funcionamiento de los partidos y movimientos políticos, de los procesos electorales y se dictan otras disposiciones. Diario Oficial, n. ${ }^{\circ} 48.130$, 14 de julio del 2011, Bogotá.

Congreso Nacional de la República (29 de diciembre del 2011). Ley 1496 del 2011, por medio de la cual se garantiza la igualdad salarial y de retribución laboral entre mujeres y hombres, se establecen mecanismos para erradicar cualquier forma de discriminación y se dictan otras disposiciones. Diario Oficial, n.o 48.297, 29 de diciembre del 2011, Bogotá. 
Congreso Nacional de la República (5 de julio del 2012). Ley 1542 del 2012, por la cual se reforma el artículo 74 de la Ley 906 del 2004, Código de Procedimiento Penal. Diario Oficial, n.o 48.482, 5 de julio del 2012, Bogotá.

Congreso Nacional de la República (6 de julio del 2015). Ley 1761 del 2015, por la cual se crea el tipo penal de feminicidio como delito autónomo y se dictan otras disposiciones (Rosa Elvira Cely). Diario Oficial, n. ${ }^{\circ}$ 49.565, 6 de julio del 2015, Bogotá.

Congreso Nacional de la República (16 de julio del 1996). Ley 294 de 1996, por la cual se desarrolla el artículo 42 de la Constitución Política y se dictan normas para prevenir, remediar y sancionar la violencia intrafamiliar. Diario Oficial, n. ${ }^{\circ} 42.836,22$ de Julio de 1996, Bogotá.

Congreso Nacional de la República (12 de agosto de 1996). Ley 311 de 1996, por la cual se crea el Registro Nacional de Protección Familiar y se dictan otras disposiciones. Diario Oficial, n. ${ }^{\circ}$ 42.855, 14 de agosto de 1996, Bogotá.

Congreso Nacional de la República (26 de agosto del 2005). Ley 985 del 2005, por medio de la cual se adoptan medidas contra la trata de personas y normas para la atención y protección de las víctimas de la misma. Diario Oficial, n. ${ }^{\circ} 46.015,29$ de agosto del 2005, Bogotá.

Congreso Nacional de la República (2 de julio del 2013). Ley 1639 del 2013, por medio de la cual se fortalecen las medidas de protección a la integridad de las víctimas de crímenes con ácido y se adiciona el artículo 113 de la Ley 599 del 2000. Diario Oficial, n. 48.839 del 2 de julio del 2013, Bogotá.

Congreso Nacional de la República (25 de julio del 2016). Ley 1799 del 2016, por medio de la cual se prohíben los procedimientos médicos y quirúrgicos estéticos para menores de edad y se dictan otras disposiciones. Diario Oficial, n. ${ }^{\circ} 49.945,25$ de julio del 2016, Bogotá.

Congreso Nacional de la República (15 de julio del 2005). Ley 972 del 2005, por la cual se adoptan normas para mejorar la atención por parte del Estado colombiano de la población que padece de enfermedades ruinosas o catastróficas, especialmente el viH/sida. Diario Oficial, n.o 45.970, 15 de julio del 2005, Bogotá.

Constitución Política de Colombia, publicada en la Gaceta Constitucional No. 116 del 20 de julio de 1991. Disponible en: http://www.secretariasenado.gov.co/senado/basedoc/ constitucion_politica_1991.html 


\section{Tratados InTERnacionales}

Convención Americana sobre Derechos Humanos (1969). San José, Costa Rica 7 al 22 de noviembre de 1969.

Convención de las Naciones Unidas contra la Delincuencia Organizada Transnacional (2000). Suscrita en diciembre del 2000, en Palermo, Italia.

Convención Internacional para prevenir, sancionar y erradicar la violencia contra la mujer. (1994). Suscrita en la ciudad de Belem Do Para, Brasil, el 9 de junio de 1994.

ONU. Convención sobre la Eliminación de Todas las Formas de Discriminación contra la Mujer (CEDAw) (1979). Aprobada por la Asamblea General de Naciones Unidas, entrada en vigencia el 3 de septiembre de 1981.

Declaración Universal de Derechos Humanos. (1948). Adoptada y proclamada por la Asamblea General de Naciones Unidas en su resolución 217 A (III), de 10 de diciembre de 1948.

ONu. Oficina del Alto Comisionado para los Derechos Humanos (1999). Protocolo facultativo de la Convención sobre la Eliminación de Todas las Formas de Discriminación contra la Mujer, adoptado por la Asamblea General de las Naciones Unidas el 6 de octubre de 1999. Recuperado de https://www.ohchr.org/SP/ProfessionalInterest/Pages/ OPCEDAW.aspx

Protocolo para Prevenir, Reprimir y sancionar la Trata de Personas, especialmente Mujeres y Niños (2000). Complementa la Convención de las Naciones Unidas contra la Delincuencia Organizada Transnacional. Suscrito en Palermo, Italia.

\section{JURISPRUDENCIA CORTE CONSTITUCIONAL}

Corte Constitucional (abril del 2009), Sentencia T-291. [M. P. Clara Elena Reales]. Bogotá.

Corte Constitucional (noviembre de 1997). Sentencia C-622. [M. P. Hernando Herrera Vergara]. Bogotá.

Corte Constitucional (septiembre de 1998). Sentencia C-481. [M. P. Alejandro Martínez Caballero]. Bogotá. 
Corte Constitucional (febrero del 2000). Sentencia C-112. [M. P. Alejandro Martínez Caballero]. Bogotá.

Corte Constitucional (septiembre del 2006). Sentencia C-804. [M. P. Humberto Antonio Sierra Porto]. Bogotá.

Corte Constitucional (diciembre del 2015). Sentencia C-754. [M. P. Gloria Stella Ortiz Delgado]. Bogotá

Corte Constitucional (noviembre del 2016). Sentencia C-659. [M. P. Aquiles Arrieta Gómez]. Bogotá.

Corte Constitucional (enero del 2001). Sentencia C-007. [M. P. Eduardo Montealegre Lynett]. Bogotá.

\section{REFERENCIAS}

Ballesteros, C. (2015). La mujer y el ejercicio efectivo del poder en Colombia, una cuestión de derechos humanos. Revista Verba Iuris, 33, Recuperado de https://revistas.unilibre. edu.co/index.php/verbaiuris/article/view/27/24

Bernal Pulido, C. (2008). El Derecho de los Derechos. Universidad Externado de Colombia. Bogotá

Facio, A. (1992). Cuando el género suena cambios trae. Metodología para el análisis de género del fenómeno legal. San José: ILANUD.

Forero, J. (2014). El valor superior de la justicia en la Unión Europea. Especial referencia al Estado Constitucional Social y Democrático de Derecho Español en Revista Verba Iuris, 31, Recuperado de https://revistas.unilibre.edu.co/index.php/verbaiuris/article/ view/59/53

González, G. (2016). Mujer y legislación: una cuestión de género. Bogotá: ILAE.

González, O. (2016). La omisión legislativa como hecho generador de la responsabilidad patrimonial del Estado. Revista Verba Iuris, 5, Recuperado de del 2018 de https://revistas. unilibre.edu.co/index.php/verbaiuris/article/view/5/2 
Guarín, E. (2015). Una aproximación filosófico-jurídica al sentido de la expresión: "Realización efectiva de los derechos". Revista Verba Iuris, 34. Recuperado de https://revistas. unilibre.edu.co/index.php/verbaiuris/article/view/16/14

Instituto de Medicina Legal y Ciencias Forenses (INMLCF) (julio del 2017). Comportamiento del homicidio 2017. Instituto Nacional de Medicina Legal y Ciencias Forenses. Forensis datos para la vida.

Instituto de Medicina Legal y Ciencias Forenses (INMLCF ). (julio del 2017). Exámenes médico-legales por presunto delito sexual. Instituto Nacional de Medicina Legal y Ciencias Forenses. Forensis datos para la vida.

Instituto de Medicina Legal y Ciencias Forenses (INMLCF ) (s.f.). Boletín epidemiológico. Violencia de género en Colombia. Análisis comparativo de las cifras de los ańos 2014, 2015 y 2016. Instituto Nacional de Medicina Legal y Ciencias Forenses. Grupo Centro de Referencia Nacional sobre Violencia. pp. 5, 11 y 17.

Malaver, C. El Tiempo. (5 de septiembre del 2014). Van 15 mujeres atacadas con ácido este año en Bogotá. Recuperado de: http://www.eltiempo.com/archivo/documento/ CMS-14486957

InfoSIDA (9 de marzo del 2017). Medicamentos contra el VIH durante el embarazo y parto. Recuperado de: https://infosida.nih.gov/education-materials/fact-sheets/24/70/ medicamentos-contra-el-vih-durante-el-embarazo-y-parto

Noticias RCN. (7 de enero del 2016). El 73 \% de víctimas de quemaduras con ácido son mujeres. Recuperado de: http://www.noticiasrcn.com/nacional-pais/ el-73-las-victimas-quemaduras-acido-son-mujeres-segun-medicina-legal

Portal del Instituto Colombiano de Bienestar Familiar. Primera Infancia. Madres Comunitarias. Recuperado de: http://www.icbf.gov.co/portal/page/portal/PrimeraInfanciaICBF/ Madres

ONU. Convención sobre la Eliminación de Todas las Formas de Discriminación contra la Mujer (CEDAw) (2004). Recomendación general No. 25, sobre el párrafo 1 del artículo 4 de la Convención sobre la eliminación de todas las formas de discriminación contra la mujer, referente a medidas especiales de carácter temporal. Recuperado de: https://www. refworld.org.es/publisher,CEDAW,GENERAL,,52d905144,0.html 